\title{
Peptides of the gut and brain: the cholecystokinins
}

\author{
By G. J. Dockray, MRC Secretory Control Group, Physiological Laboratory,

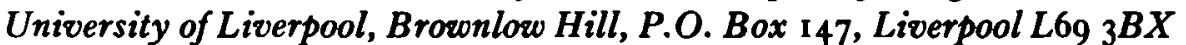

The idea that peptides are able to act as extracellular molecular messengers can be traced to the work of Bayliss and Starling and, in particular, to their discovery in 1902 that the reflex secretion of pancreatic juice caused by duodenal acidification was due to a blood-borne factor, secretin (Bayliss \& Starling, 1902). Only 3 years later, Scott (1905) drew attention to similarities in the histological properties of nerve cells and secretory cells of the gut. He clearly saw that neurones were true secretory cells, that their secretory products might be of a proteinaceous or peptide nature, and that their secretions could be the means of neuronal communication. Although the work of Bayliss \& Starling (1902) had immediate impact, Scott's (1905) work was largely ignored, and it is only in the last decade or so that we have come to appreciate the wide range of different systems in which peptides are able to act as regulatory molecules. In the gastrointestinal tract, they can be hormones or local (paracrine) regulators, and in both brain and gut they can be neurotransmitters. One of the important unifying ideas in this area is that the same or closely related peptides can be found in each of these different systems, and so are likely to have a variety of physiological roles.

In addition to roles in brain and gut, certain peptides also appear to be involved in signalling to the brain information about nutrient delivery to the gut, and may therefore be considered integrators of brain and gut function. The present paper will deal with general aspects of the distribution and chemistry of brain-gut peptides and will deal specifically with the way that peptides can act as integrators of brain and gut. The field is considerable (for reviews of individual peptides, see Gregory, 1982) and particular attention will be given to cholecystokinin (CCK) as this is one of the most intensively studied brain-gut peptides.

\section{Distribution: organization and functional aspects}

Within the gastrointestinal tract regulatory peptides occur in specialized epithelial endocrine cells, in intrinsic neurones and in extrinsic (mainly afferent) nerve fibres. In the gut, and in the central nervous system (CNS), each peptide has a distinctive pattern of distribution (Fig. I). For instance CCK occurs in mucosal endocrine cells in the proximal small intestine, and in intrinsic nerves of the intestinal submucous plexus that project to the mucosa (Dockray et al. 1984). In brain, CCK is particularly abundant in cortical, mesolimbic and hypothalamic neurones (Dockray, 1983). There is no reason to suppose that in the brain CCK has functions concerned with the control of pancreatic enzyme secretion or gall bladder contraction which are the primary functions of the hormone released from 


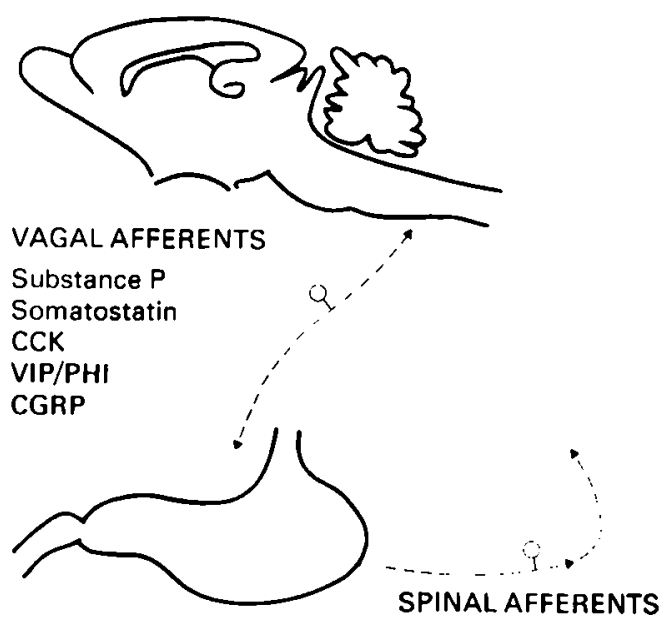

$\begin{array}{ll}\text { GUT INTRINSIC } & \text { GUT ENDOCR } \\ \text { NEURONES } & \text { Gastrin } \\ \text { Substance P } & \text { CCK } \\ \text { VIP/PHI } & \text { Secretin } \\ \text { Opioids } & \text { GIP } \\ \text { Somatostatin } & \text { Glucagon } \\ \text { Bombesin/GRP } & \text { Motilin } \\ \text { NPY } & \text { Neurotensin } \\ \text { CCK } & \text { PYY }\end{array}$

\section{SPINAL AFFERENTS}

Substance $P$

Somatostatin VIP/PHI

CGRP

Bombesin/GRP

Fig. 1. Schematic representation of the distribution of peptides in the gut. The main peptides produced in mucosal endocrine cells, gut intrinsic neurones and extrinsic neurones (spinal and vagal afferents) are listed. All these peptides are also found in the central nervous system (CNS). Note overlaps in distribution, so that the same peptide may have several different cellular origins. Note also that peptides are represented at every level on the pathway by which visceral information is conveyed to the CNS. VIP, vasoactive intestinal polypeptide; PHI, peptide with $\mathrm{N}$-terminal histidine, C-terminal isoleucine amide; GRP, gastrin-releasing peptide; NPY, neuropeptide with $\mathrm{N}$-terminal tyrosine and C-terminal tyrosine amide; CCK, cholecystokinin; GIP. gastric inhibitory polypeptide; PYY, gut peptide with $\mathrm{N}$-terminal tyrosine and $\mathrm{C}$-terminal tyrosine amide; CGRP. calcitonin gene-related peptide.

gut endocrine cells. Instead it is plausible to suppose that CCK has separate functions in different systems, and as a consequence that there are mechanisms to maintain specificity of action in different systems (Dockray \& Hopkins, I982). For instance the blood-brain barrier excludes circulating CCK from the CNS, although this does not prevent penetration in regions where the barrier is leaky or non-existent (Oldendorf, r981).

\section{Biochemical aspects}

Most brain-gut peptides occur in more than one molecular form. The heterogeneity is often attributable to variation in the pathways of biosynthesis. Thus, all known biologically active peptides are made first as large precursors that are subsequently modified by mechanisms we know as post-translational processing; these include cleavage of the precursor chain and the addition of 
prosthetic groups, e.g. C-terminal amides, sulphation, glycosylation. The form of CCK used most often in the laboratory is the octapeptide, or CCK8; this has two modifications to its primary sequence: sulphation of the tyrosine and C-terminal amidation, both of which are essential for biological activity. It has been known for nearly 20 years that $\mathrm{CCK}$ is part of the same family as gastrin which is the hormone controlling gastric acid secretion. Both share a common C-terminal tetrapeptide amide that is also the minimal active fragment with biological activity. This accounts for the similar biological and immunochemical properties of the two peptides. In fact, the first report of the presence of this group of substances in brain, made by Vanderhaeghen et al. (1975), referred to gastrin-like peptides although it is now clear that this activity was largely due to CCK8 (Dockray, 1983).

The sequence of the gene encoding the $\mathrm{CCK}$ precursor has recently been elucidated. In the rat, the precursor corresponds to a linear peptide of I 5 amino acid residues (Deschenes et al. 1984). Post-translational processing of the chain at the -glycine-arginine-arginine- tripeptide sequence liberates the amidated C-terminus of CCK8; this processing step, together with cleavage at other arginine residues and sulphation of the tyrosine, can account for the production of the known biologically active products, i.e. CCK8 itself and its N-terminally extended forms $\mathrm{CCK}_{33}, 39$ and 58 . In addition there are flanking peptides to the $\mathrm{C}$ - and $\mathrm{N}$-terminus of the main active peptides. Some of the $\mathrm{N}$-terminal fragments of $\mathrm{CCK}_{33}, 39$ and $5^{8}$ have already been isolated (Eng et al. 1983) and we have recently found the C-terminal flanking peptide of the precursor (Varro \& Dockray, 1986). All the products of synthesis are thought to be stored and secreted together. We cannot assume that the flanking peptides are not biologically active and by analogy with other systems there may well be novel activities associated with these peptides that are waiting to be identified.

The patterns of post-translational processing are different in different cells expressing the CCK gene. In brain, the main active product appears to be CCK8, while in intestine there occurs not only $\mathrm{CCK} 8$ but also $\mathrm{CCK}_{33}, 39$ and 58 . Evidently, then, with regard to biosynthetic mechanisms, there are important differences between cells in brain and gut expressing the CCK gene. At present, we do not know how these differences are regulated, and we do not know their physiological significance.

\section{CCK as a brain-gut integrator}

The realization that $\mathrm{CCK}$ occurs in high concentrations in both the CNS and the gut has prompted interest in the possibility that it might act as an integrator of brain-gut function. This interest has been stimulated by the observation that CCK given peripherally exerts important effects on behaviour, and of particular significance in this context is the fact that CCK has strong satiety effects. This effect was first characterized by Gibbs et al. (1973) and has since been confirmed in many species using a variety of different models.

Several lines of evidence indicate that the vagus, and particularly the afferent 
fibres, are important for the satiety effect of peripherally administered CCK. Thus the effect is abolished by lesion of the gastric vagal branches (Smith et al. I98I), by capsaicin which lesions small-diameter primary afferent fibres (Ritter \& Ladenheim, 1985), by cutting afferent vagal rootlets (Smith et al. 1985) and lesioning the parts of the medulla where vagal afferents terminate (Crawley \& Schwaber, 1984).

\section{Peptides and visceral afferent mechanisms}

There are several different ways in which peptides could be involved in signalling visceral information to the CNS. First, it is known that peptides occur in visceral afferent fibres. Over $50 \%$ of gastric spinal afferents are known to contain substance $\mathrm{P}$ (Sharkey et al. 1984); antibodies to other peptides e.g. neurokinin $\alpha$, calcitonin gene-related polypeptide, $\mathrm{CCK}$ and vasoactive intestinal polypeptide (VIP), also reveal immunoreactive material in spinal afferents and it is likely that the same peptides occur in vagal afferents (see Dockray \& Sharkey, I986). These peptides are therefore potential transmitters at the central endings of visceral afferent neurones. In addition, they are also transported towards the periphery, and there is reasonable evidence to suggest that certain active peptides may be released at the peripheral terminals of afferent fibres in the gut, although the physiology of this system remains poorly understood (Dockray \& Sharkey, 1986). Second, gut hormones released into the circulation during digestion, or secreted locally, could modulate visceral afferent discharge by acting either directly on afferent fibres, or indirectly via changes in gut motility or secretion. Electrophysiological recordings of single vagal afferent fibres from sheep duodenum indicate that CCK (and other peptides/transmitters) influences mechanoreceptor discharge secondary to changes in motility (Cottrell \& Iggo, 1984). This does not, however, exclude direct effects on nerve fibres in other species or tissues. Third, circulating peptides could act directly on the CNS by either penetrating or by-passing the blood-brain barrier.

\section{Peripheral actions of CCK on brain-stem neurones}

In order to study the mechanisms by which peripherally administered CCK might act on the CNS we have made extracellular recordings of the activity of single neurones in the dorso-medial medulla. These cells are at the first level at which vagal afferents from the stomach are able to evoke CNS effects. Neurones that have an input from the stomach can be identified by changes in their firing rate in response to gastric distension. The primary signal in this system is the volume of the gastric contents, rather than their composition. The stimulus can be either a single dose of saline ( $0.14 \mathrm{M}$-sodium chloride) into the stomach, or the infusion of saline into the stomach at a rate that mimics the physiological delivery of liquid meals.

Two sorts of cell in the brain stem can be readily distinguished (Raybould et al. 1985). When the stomach is distended, one type responds with an increase in the rate of discharge up to five times the resting level. This cell type also responds to 
CCK8 given intravenously in doses of $1-10 \mathrm{nmol}$, and again the response is an increase in firing. The other type of cell shows the opposite response. It is depressed by gastric distension, and in some cases its discharge is completely inhibited. CCK given intravenously in doses of $\mathrm{I}-\mathrm{IO}$ nmol produces a similar inhibition. This pattern of response is quite consistent. Although there are a few brain-stem cells which respond to intravenous $\mathrm{CCK}$, but not gastric distension, the evidence strongly points to the fact that $\mathrm{CCK}$ given intravenously acts on the same pathway by which information about gastric volume is handled by the brain. So far as we can tell there is no differential localization in the brain stem of the two cell types: both can be found in nucleus tractus solitarius and in nearby regions of the dorso-medial medulla.

On their own these findings do not tell us whether CCK given intravenously is acting peripherally or centrally. It is conceivable that CCK penetrates the blood-brain barrier and acts directly on cells with a gastric input. It is known, for example, that like many other CNS cells, those in the medulla can respond to iontophorectically applied CCK (Ewart \& Wingate, 1983). Two lines of evidence help clarify the issue. First, if CCK is given by close arterial injection to the coeliac artery, similar results are obtained to intravenous injection. But there is one important difference: the range of effective doses is reduced ro to roo-fold. Thus a good response is obtained with 100 pmol or less given intra-arterially, and again the pattern of response to CCK and gastric distension is similar for both excited and depressed cells (Raybould et al. 1985). Second, vagotomy completely abolishes the effect of both CCK intravenously and gastric distension (H. E. Raybould, R. J. Gayton and G. J. Dockray, unpublished results). Together these lines of evidence indicate that CCK is able to act at a site within the splanchnic bed to change the discharge of brain-stem neurones through the same vagal pathway that signals gastric volume. Several different mechanisms could account for these observations, for example there could be direct effects on vagal afferents, or indirect effects secondary to motility changes in the fundus or antrum.

Gastric distension increases intragastric pressure and the increased tension in the gastric wall is the stimulus for mechanoreceptor discharge. In contrast, intravenous or intra-arterial injection of CCK has the opposite effect, it relaxes the body of the stomach. The mechanism whereby CCK decreases intragastric pressure in vivo is still uncertain. Even so, it seems unlikely that CCK simply modulates mechanoreceptor discharge via changes in tension in the gastric wall. In this context it is interesting to note that VIP produces similar effects on intragastric pressure to those of CCK. The CNS responses to VIP are, however, quite different to those of CCK. Most cells with a gastric input do not respond to VIP given intravenously, and amongst those that do, the responses frequently differ from those evoked by gastric distension (H. E. Raybould, R. J. Gayton and G. J. Dockray, unpublished results). It would appear unlikely, then, that the effects of CCK on the CNS are secondary to changes in gastric motility. In contrast, the available evidence is consistent with the idea that $\mathrm{CCK}$ acts directly on vagal afferents and that this action is responsible for the effects of the peptide on the CNS following peripheral injection. 


\section{Physiological implications and future work}

In view of the conclusions outlined previously it is interesting to note that CCK receptors have been found by autoradiography on vagal fibres (Zarbin et al. 1981), although it remains to be shown whether these binding sites are on vagal afferents or efferents. Further work is also needed to establish whether or not circulating post-prandial concentrations of CCK are sufficient to trigger the effects described here. It is, however, worth reiterating that CCK occurs in vagal afferents and is transported in them towards the periphery (Dockray et al. 1981). The release of locally high concentrations of CCK at the peripheral ends of vagal afferents could provide a mechanism for modulating the discharge of the mechanoreceptors that respond to gastric distension. This in turn might be the physiological basis for the central effects exerted by exogenous $\mathrm{CCK}$.

\section{REFERENCES}

Bayliss, W. M. \& Starling, E. H. (1902). Fournal of Physiology 28, 325-353.

Cottrell, D. F. \& Iggo, A. (1984). Journal of Physiology 354, 477-495.

Crawley, J. N. \& Schwaber, J. S. (Ig84). Brain Research 295, 289-299.

Deschenes, R. J., Lorenz, L. J., Haun, R. S., Roos, B. A., Collier, K. J. \& Dixon, J. E. (1984). Proceedings of the National Academy of Science, USA 81, 726-730.

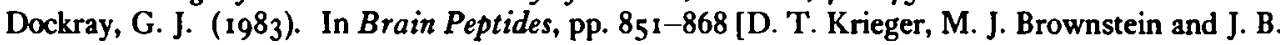
Martin, editors]. New York: Wiley Interscience.

Dockray, G. J., Gregory, R. A., Tracy, H. J. \& Zhu, W.-Y. (1981). Fournal of Physiology 314, $501-5 \mathrm{II}$.

Dockray, G. J. \& Hopkins, C. R. (1982). In The Functional Integration of Cells in Animal Tissues, pp. 39-56 [J. D. Pitts and M. E. Finbow, editors]. Cambridge: Cambridge University Press.

Dockray, G. J. \& Sharkey, K. A. (1986). Progress in Brain Research 67, 133-148.

Dockray, G. J., Sharkey, K. A. \& BuLock, A. J. (1984). In Function and Dysfunction of the Small Intestine, pp. 39-54 [R. M. Batt and T. L. J. Lawrence, editors]. Liverpool: Liverpool University Press.

Eng, J., Shina, Y., Pan, Y.-C., Blacher, R., Chang, M., Stein, S. \& Yalow, R. S. (1983). Proceedings of the National Academy of Science, USA 80, $638 \mathrm{I}-6385$.

Ewart, W. R. \& Wingate, D. L. (1983). American fournal of Physiology 244, G613-G6r 7 .

Gibbs, J., Young, R. C. \& Smith, G. P. (1973). Nature 245, 323-325.

Gregory, R. A. (1982). British Medical Bulletin 38, 219-313.

Oldendorf, W. H. (1981). Peptides 2, Suppl. 2, 109-1 11.

Raybould, H. E., Gayton, R. J. \& Dockray, G. J. (1985). Brain Research 342, 187-190.

Ritter, R. C. \& Ladenheim, E. E. (1985). American foumal of Physiology 248, R5OI-R504.

Scott, F. H. (1905). Brain 28, 506-526.

Sharkey, K. A., Williams, R. G. \& Dockray, G. J. (1984). Gastroenterology 87, $914-921$.

Smith, G. P., Jerome, C., Cushin, B. J., Eterno, R. \& Simansky, K. J. (1981). Science 213, 1036-1037.

Smith, G. P., Jerome, C. \& Norgren, R. (1985). American fournal of Physiology 249, R638-R64r.

Vanderhaeghen, J. J., Signeau, J. C. \& Gepts, W. (1975). Nature 257, 604-605.

Varro, A. \& Dockray, G. J. (1986). Brain Research 376, 2 13-216.

Zarbin, M. A., Wamsley, J. K., Innis, R. B. \& Kuhar, M. J. (1981). Life Science 29, 697-705. 